\title{
El corpus literario personal de los alumnos del último curso de Educación Infantil. Datos de un estudio
}

The personal literary corpus of the students of the last course of Pre-school education. Results of a study

\author{
Dra. Beatriz Sánchez Hita \\ Departamento de Didáctica \\ de la Lengua y la Literatura. \\ Universidad de Cádiz \\ beatriz.sanchez@uca.es \\ Lourdes Sánchez Vera \\ Departamento de Didáctica \\ de la Lengua y la Literatura. \\ Universidad de Cádiz \\ lourdes.sanchez@uca.es
}

\begin{abstract}
Resumen
En las siguientes páginas se analizan los principales resultados de un estudio realizado en el curso académico 2014/2015 a los alumnos que cursaban la asignatura Literatura Infantil y Fomento de la Lectura del Grado en Educación Infantil, a los que se les solicitó que indicasen cinco libros que, desde su punto de vista, no pudiesen faltar en su biblioteca de aula, argumentando la elección. A partir de estos datos ha sido posible conocer cuáles son los títulos, géneros y autores con una eventual mayor presencia en el aula, así como dilucidar qué razones son las que llevan a un futuro docente a decantarse por una determinada obra. De manera paralela se ofrece un muestreo del conjunto de editoriales y autores presentes en la selección completa del alumnado.
\end{abstract}

\begin{abstract}
This paper analyzes the main results of a study performed during the academic year 2014/2015 to the students who were registered and studying the subject 'Children's literature and promotion of the reading of the degree in Pre-school education. They were requested to select five books that, from their point of view, needed to be in their classrooms libraries, always arguing the election. Thanks to this data we discovered the titles, genres and authors with an eventual greater presence in the classroom, as well as the reasons why the future teachers prefer certain works. We also offer as annexes a sampling of the set of publishers and authors that were present in the full selection of students.
\end{abstract}

Palabras clave: Literatura infantil, Géneros literarios, Biblioteca de aula, Educación Infantil, Panorama editorial

Keywords: Children's literature, Literary genre, Classroom library, Pre-school education, Editorial Panorama 


\section{Introducción}

Durante el curso académico 2014/2015, como parte de las prácticas realizadas en la asignatura Literatura Infantil y Fomento de la Lectura del Grado en Educación Infantil de la Universidad de Cádiz, los alumnos realizaron en pequeños grupos una propuesta de diseño y selección de materiales para una posible biblioteca de aula, para la etapa de Educación Infantil. Esta actividad junto a otras llevó a los discentes a buscar obras e información sobre las mismas, ampliando sus conocimientos sobre el corpus de la Literatura Infantil adecuado para la edad. Conviene indicar que en los actuales planes del grado de la Universidad de Cádiz la asignatura se sitúa en el segundo semestre del último curso, por lo que cuando el alumno cursa la materia posee algunos conocimientos sobre qué obras pueden ser adecuadas para la etapa y sus posibilidades de trabajo adquiridos en asignaturas no necesariamente vinculadas a la Didáctica de la Lengua y la Literatura. Asimismo, al haber completado ya los dos periodos de prácticas comprendidos en el programa de la titulación, posee cierta experiencia personal sobre qué leer y cómo leer en el aula. Todos estos factores condicionan en parte la elección, que a su vez se verá marcada siempre por inclinaciones personales.

Con el objeto de indagar en qué medida las actividades realizadas en la asignatura Literatura Infantil y Fomento de la Lectura podrían haber contribuido a ampliar una posible selección de obras por parte de los alumnos y hasta qué punto esta propiciaba la presencia de variedad de géneros, autores y formatos o se vinculaba al trabajo de determinados aspectos recogidos en el currículo - sin que estos necesariamente guardasen relación con el intento de acercar al niño al hecho literario y despertar su afición por la lectura - en la prueba de evaluación de la asignatura se pidió a los estudiantes que eligiesen cinco obras que, según su criterio, no debían faltar en su biblioteca de aula y que justificasen su decisión; para propiciar la elección libre se les indicó que se trataba de una pregunta no puntuable.

En total se obtuvieron 813 respuestas, pues no todos los alumnos indicaron cinco obras. A partir de esos datos comenzamos a trabajar corrigiendo en una primera fase los errores contenidos en los títulos y autores aportados por los alumnos y uniendo las referencias diferentes hechas sobre una misma obra. En dicho proceso se añadieron además los datos sobre los ilustradores de las obras y la editorial responsable de la tirada de las mismas, pues pensamos que esta información, sumada a otros estudios, puede ser de utilidad para valorar qué empresas son las que potencialmente pueden tener una mayor presencia en el aula. De igual modo, una vez que se completó la información de cada entrada - a partir de los datos aportados por las propias editoriales-, comprobamos a qué público estaban destinadas las obras para verificar si había que suprimir alguna del listado general por ser demasiado compleja para incluirla en la biblioteca de aula.

Asimismo, una vez analizados los datos obtenidos se ha tenido en consideración en qué medida las elecciones de los alumnos guardan relación con lo dispuesto en el currículo para la etapa educativa en el ámbito andaluz, para lo que se ha tomado como referencia prioritariamente la Orden de 5 de agosto de 2008, por la que se desarrolla el Currículo correspondiente a la Educación Infantil en Andalucía así como el Real Decreto 1630/2006, por el que se establecen las enseñanzas mínimas del segundo ciclo de 
Educación Infantil, ya que los contenidos curriculares de la etApa no se han visto afectados por la implantación de la LOMCE.

\section{La selección}

Como se indicó arriba, en total fueron 813 las entradas que generó la elección de los alumnos. Tras un primer cotejo fue preciso eliminar una obra que tenía una única cita por ser imposible con los datos aportados determinar qué título se había querido indicar, así como lo que parece ser un material docente empleado para trabajar conceptos: $E l$ libro de los círculos, lo que redujo la muestra a 811 respuestas a partir de las que se comenzó a delimitar cuántas eran las obras que realmente se podían considerar aptas para la etapa educativa.

De entre el conjunto de textos del listado llamó nuestra atención la inclusión de varios dirigidos a lectores de más de 9, 10 y 12 años según las editoriales, entre los que se localizan varios clásicos de la literatura infantil y juvenil como Los viajes de Gulliver de Jonathan Swift (1726), El libro de la selva de Rudyard Kipling (1894), Alicia en el país de las maravillas de Charles Lutwidge [Lewis Carroll] (1865), El Principito (1943) de Antoine de Saint-Exupéry, la heptalogía Las crónicas de Narnia de Clive Staples Lewis (1950-1956), La historia interminable de Michael Ende (1979) o Charlie y la fábrica de chocolate (1964) y Matilda (1988) de Roald Dahl, así como otros éxitos más recientes Mi amiga secreta de Juana Neira (2008) o El árbol rojo de Shaun Tan (2001), que no resultarían adecuados para un trabajo autónomo por parte del alumno. Conviene precisar aquí que en el caso de El Principito suele indicarse que la versión empleada sería la lanzada en formato de pop-up por la editorial Salamandra, lo que haría factible afrontar una lectura-visionado de imágenes guiada por el profesor; asimismo se da además la circunstancia de que al menos una alumna de uno de los grupos había realizado esta actividad en el periodo de prácticas y había expuesto su actividad ante su grupo en otra asignatura de la carrera, lo que pudo condicionar la elección. Algo similar pensamos que podría hacerse también con el álbum El ladrón de palabras de Nathalie Minne (2011), lo que nos lleva a mantener estas obras en el cómputo general y a excluir las demás. Hemos mantenido igualmente el Gran libro de los retratos de animales de Svjetlan Junakovic (2006), pues puede ser útil para introducir al niño en el mundo del arte.

Se han eliminado las referencias a dos cómics dirigidos a mayores de 9 años: Hora de aventuras de Ryan North y la colección de Gerónimo Stilton, pues aunque es probable que los niños se pudiesen sentir atraídos por ellos por contar con series paralelas de dibujos animados, difícilmente podrían acceder a sus contenidos. De igual modo, se ha eliminado Marcelino pan y vino de José Manuel Sánchez.

Conviene advertir que se han dejado aquellas obras en las que el límite de edad se establecía en los 6, 7 u 8 años, pues las características de las mismas y el diferente desarrollo en la capacidad de leer y escribir en la etapa de Educación Infantil - ya sea de manera autónoma, ya con el maestro como mediador-, hacen factible el acceso a estos textos, entre los que se encuentra algún libro de poesía y teatro o Platero y yo, que 
ha sido trabajado en adaptaciones diversas o desde el original en no pocos centros con motivo del centenario de la primera edición de la obra en $2014 .^{9}$

Tras considerar todas estas cuestiones y revisar los datos iniciales, las respuestas válidas serían 794 y estas se repartirían en un total de 242 obras (frente a las 260 iniciales), firmadas por 180 autores y diversos equipos editoriales. En la selección de textos encontramos obras literarias y no literarias, aunque predominan las primeras y dentro de estas el género narrativo es el dominante; entre las segundas junto a libros-juego encontramos diccionarios, textos históricos, volúmenes destinados al trabajo de rutinas, así como la revista Caracola con una única elección. Si atendemos a la clasificación de las obras que, según Colomer y Durán (2001, pp. 232-233), ofrece el mercado editorial para niños de cero a seis años la mayor parte de los formatos quedan recogidos en este listado. De manera concreta las investigadoras recogen las siguientes categorías: libros de imágenes, abecedarios y silabarios, poemarios y cancioneros, cuentos, adaptaciones de cuentos tradicionales, adaptaciones no tradicionales, álbumes, libros mudos, Pop Up o libros juego, documentales o libros de conocimiento, cuadernos de actividades, gadgets promocionales y publicaciones periódicas (2001, pp. 232-233).

Aprovechamos para indicar aquí que a la hora de agrupar las obras se han incluido dentro del género literario correspondiente aquellos álbumes ilustrados que aúnan imagen y texto literario, pues entendemos que con independencia de las características propias de este tipo de libro pujante en la producción literaria infantil en los últimos años, tal y como recoge Durán (2007, p. 32 ) — que vincula además la producción del álbum ilustrado a la "evolución cultural, social, tecnológica y artística de la Era de la Comunicación" y lo relaciona con otras manifestaciones como el cómic o el cine (2007, p. 32)-, el texto literario presente en el mismo posibilita el acercamiento a un género u otro, de los que podríamos denominar tradicionales, simplificados en lo que atañe a la literatura infantil como especificaba Tamés (1985) en narrativa-cuento, poesía y teatro (cit. en Cervera, 1991, p. 65).

En relación con esto último, conviene precisar que "las características del álbum ilustrado lo convierten en un recurso idóneo tanto para la iniciación a la competencia literaria como para el afianzamiento de la habilidad lectora en los jóvenes" (Hoster y Lobato, 2007, p. 120), aspecto este que consideramos de especial relevancia en Educación Infantil por ser esta una etapa en la que el niño comienza a adquirir habilidades lectoras y se aproxima a la literatura. Y es que, en la citada etapa educativa a esos conocimientos iniciales, innatos en palabras de Mendoza Fillola (2008), que permiten al niño advertir el carácter literario de ciertos textos, que recibe de manera oral principalmente, se suman otros los adquiridos a través del aprendizaje y la práctica lectora-receptora de textos, desde los que irá configurando sus gustos e intereses y que en algunos casos lo llevarán a la producción de textos (Mendoza Fillola, 2008).

\footnotetext{
${ }^{9}$ Como apuntaba el propio Juan Ramón Jiménez en el "Prologuillo" a la edición de 1917 la obra en sus orígenes no estaba dirigida a los niños de manera específica, pero en 1914 por necesidades económicas y animado por Giner de los Ríos publicó en la colección titulada Biblioteca de la Juventud de la editorial La Lectura, tenía aquella edición 63 capítulos y llevaba por título Platero y yo: elegía andaluza; a esta edición sigue la de 1917 con 138 capítulos en la editorial Calleja.
} 
De manera concreta, las obras literarias representan el $91,18 \%$ con un total de 724 elecciones, mientras que las no literarias suponen el 8,69\% con 69 elecciones, a las que debe añadirse el 0,13\% representado por la revista Caracola.

Para agrupar las obras se han tomado en consideración lo que las propias editoriales apuntaban sobre la clasificación de las mismas, así como los datos contenidos en los catálogos de diferentes librerías. ${ }^{10}$

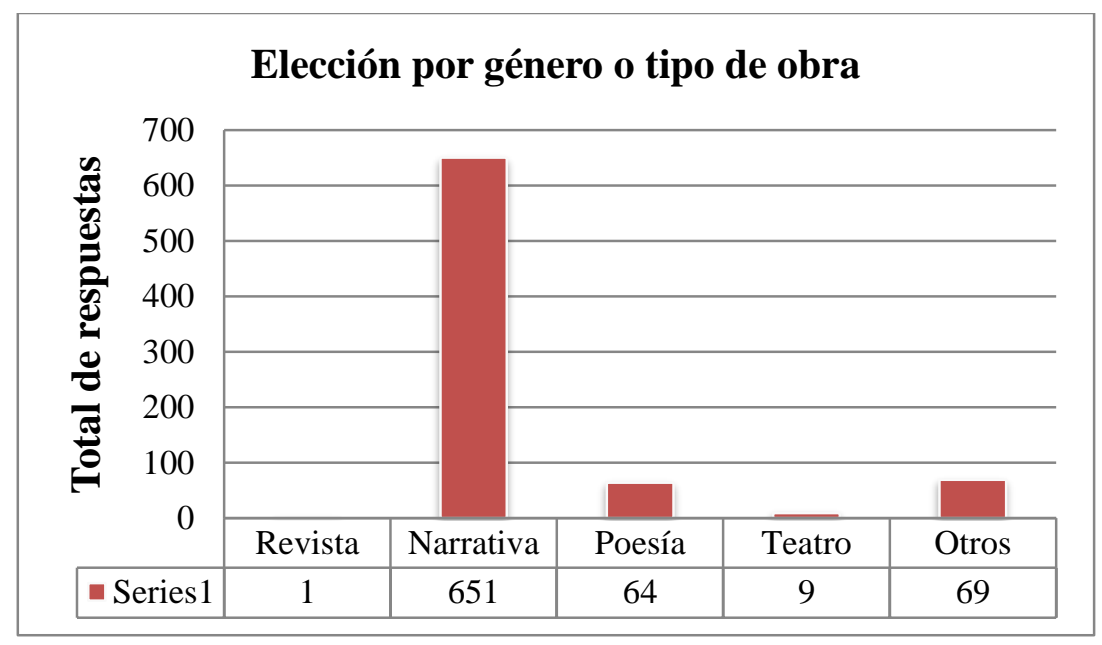

Figura 1. Respuestas-obras

Si representamos estos datos a modo de porcentaje la presencia de la narrativa se hace aún más evidente, mientras que las revistas y el teatro apenas se verían reflejados:

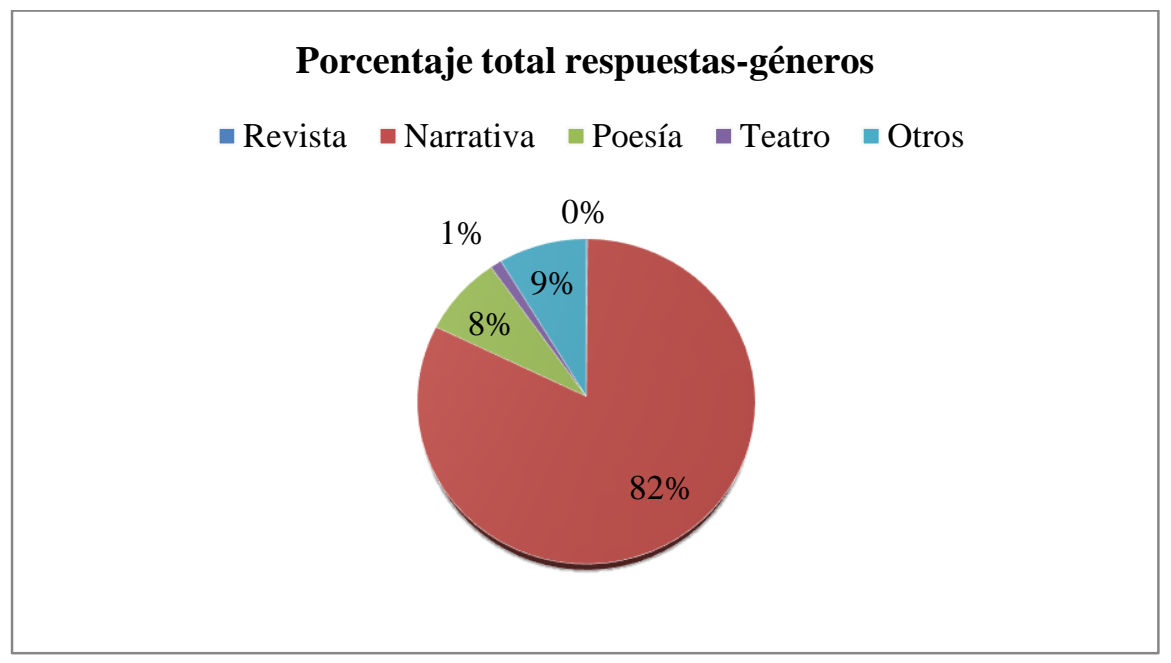

Figura 2. Porcentaje de la presencia de géneros en la selección

\footnotetext{
${ }^{10}$ Conviene precisar en este punto que el catálogo de la Biblioteca Nacional de España no arroja información sobre el género al que pertenecen, de acuerdo con lo que sucede con la CDU donde a la literatura infantil le corresponden los dígitos 087.5:82, sin que se especifique el género cuando no se trata de antologías. Pueden verse las indicaciones al respecto en la siguiente dirección de la Biblioteca Nacional de España: https://goo.gl/5zQDVy.
} 
Estos resultados varían si lo que se tiene en cuenta es el total de obras seleccionadas, aunque estimamos más significativo el dato anterior por responder a la elección concreta realizada por los alumnos.

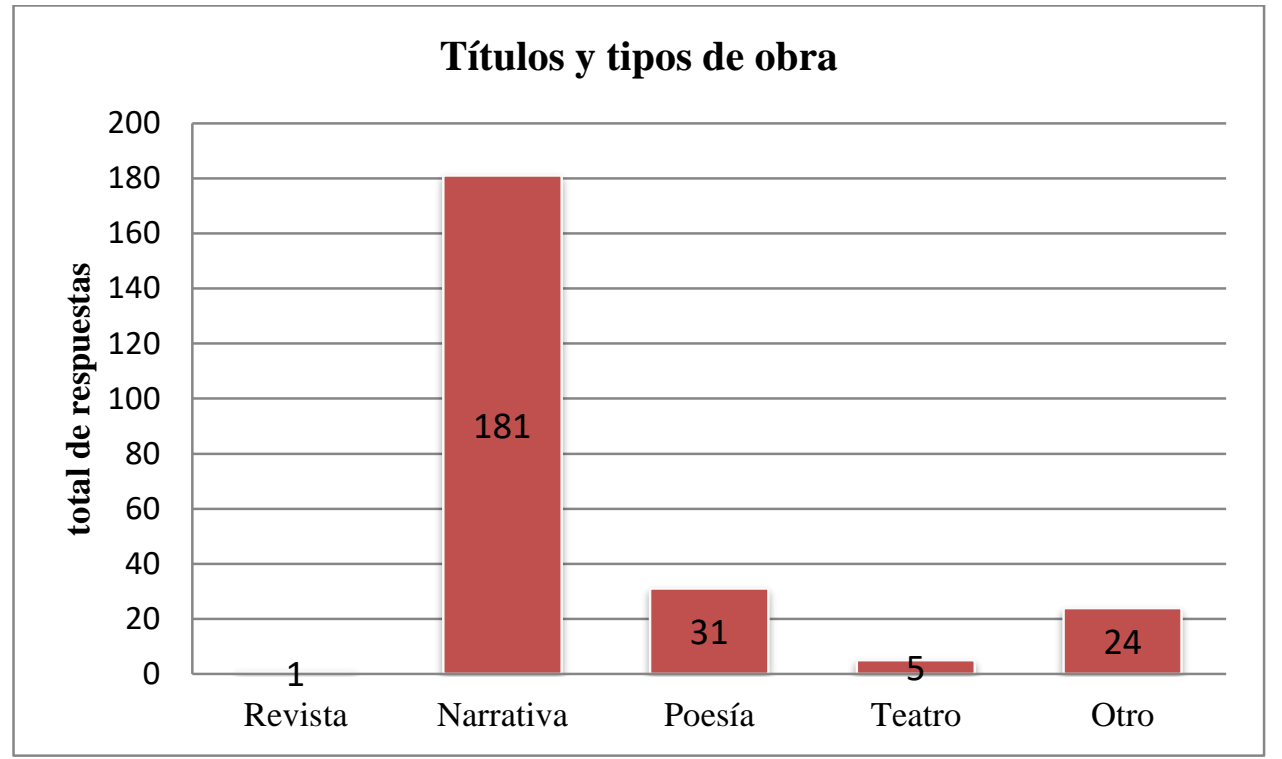

Figura 3. Total de obras según género (literario y no literario)

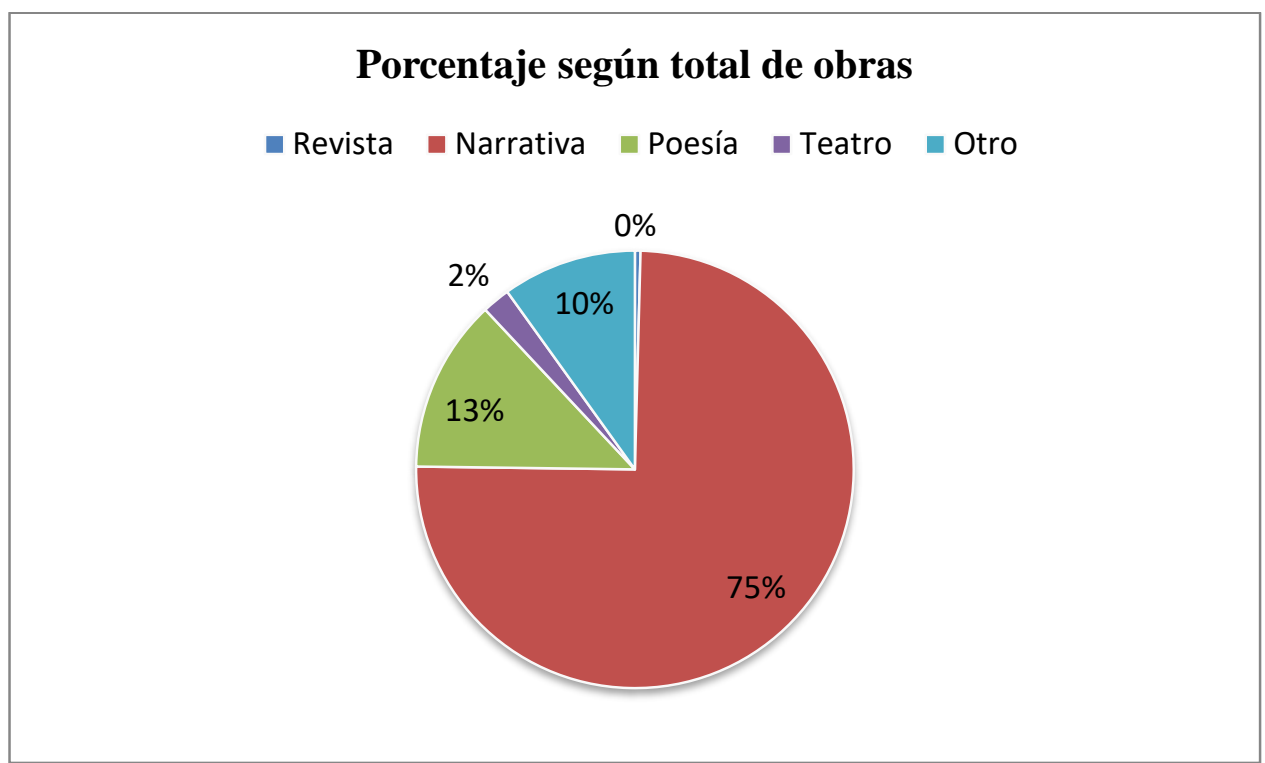

Figura 4. Porcentaje de obras según género (literario y no literario)

Entre el conjunto de títulos aportados por los alumnos se nota un predominio de las obras literarias escritas para niños por autores consagrados de LIJ y mayoritariamente por autores actuales, aunque tampoco faltan los clásicos de tradición oral, que a veces se citan a partir de las recopilaciones y versiones preparadas por Perrault o los hermanos Grimm, y en otras ocasiones se citan nuevas ediciones ilustradas o con la historia presentada de un modo diferente — valgan de ejemplo las versiones de Caperucita o Blancanieves-. 


\begin{tabular}{|l|l|l|}
\hline CAPERUCITA & BLANCANIEVES \\
\hline $\begin{array}{l}\text { Caperucita roja versión de Charles } \\
\text { Perrault. }\end{array}$ & $\begin{array}{l}\text { Blancanieves (sin indicación de qué } \\
\text { versión clásica) }\end{array}$ \\
\hline $\begin{array}{l}\text { Caperucita roja versión de Jakon y } \\
\text { Wilhelm Grimm. }\end{array}$ & $\begin{array}{l}\text { Blancanieves de Benjamin Lacombe, } \\
\text { Edelvives. }\end{array}$ \\
\hline $\begin{array}{l}\text { Confundiendo historias de Giani Rodari, } \\
\text { Kalandraka. }\end{array}$ & $\begin{array}{l}\text { Blancanieves, teatro tridimensional de } \\
\text { Jane Ray, SM. }\end{array}$ \\
\hline $\begin{array}{l}\text { La verdadera historia de Caperucita Roja } \\
\text { de Agnese Baruzzi, Ediciones B. }\end{array}$ & \\
\hline $\begin{array}{l}\text { Lo que no vio caperucita roja de Mar } \\
\text { Ferreiro, Edelvives. }\end{array}$ & & \\
\hline
\end{tabular}

Tabla 1. Versiones de clásicos

Conviene advertir aquí, que en el caso de estas obras clásicas a veces ha sido imposible determinar qué edición concreta se cita o quién firma la versión por falta de datos en la descripción, por lo que aunque se han mantenido en el cómputo general no se han considerado en el de empresas editoras o autores - los datos sobre estos dos últimos aspectos pueden verse en los Anexos 1 y 2 -

Del total de obras, diecisiete cuentan con más de diez elecciones. Entre dichos títulos predominan los pertenecientes al género narrativo - habitualmente con formato de álbum ilustrado- y varias obras que responden a la caracterización del libro juego, tal y como sucede con Un libro de Hervé Tullet, o que por las peculiaridades de su formato propician un tipo de lectura que acerca al niño a una determinada problemática con el fin de fomentar la integración como sucede con El libro negro de los colores, que hace posible que el niño tome conciencia de cómo "ve" alguien con discapacidad visual. En las razones que apuntan para su elección se aprecia que el alumnado valora el uso de los textos narrativos por su utilidad para tratar contenidos conceptuales y aspectos relacionados con la personalidad del niño y solo puntualmente se destaca el uso de estas obras para divertir al niño. Esto es algo que llama aún más la atención cuando nos acercamos al género poético, del que entre las obras con más de diez elecciones figura Todos somos especiales de Arlene Maguire y que creemos que, pese a que está escrito en verso, no tiene como objetivo principal el aproximar al niño al lenguaje poético, sino que se asemeja más al libro destinado a la autoafirmación personal y al trabajo de la diversidad - como indican los alumnos en sus respuestas-. De igual modo llama la atención que, pese a haber trabajado durante el curso de manera específica sobre la poesía y el modo de acercarla a los niños, solamente aparezcan en la recopilación unos pocos nombres de autores de dicho género, entre los que destaca Gloria Fuertes; es cierto que también aparecen algunas de las obras editadas por Antonio Rubio en la colección De la cuna a la luna de Kalandraka o varios trabajos Carlos Reviejo y Carmen Gil, pero estos tienen una menor presencia. 


\begin{tabular}{|c|c|c|c|c|c|c|c|}
\hline TÍTULO & AUTOR & ILUSTRADOR & EDITORIAL & GÉNERO & 离 & 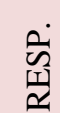 & MOTIVOS \\
\hline $\begin{array}{l}\text { ¿A qué sabe la } \\
\text { luna? }\end{array}$ & $\begin{array}{l}\text { Michael } \\
\text { Grejniec }\end{array}$ & $\begin{array}{l}\text { Michael } \\
\text { Grejniec }\end{array}$ & Kalandraka & $\begin{array}{l}\text { Narrativa } \\
\text { Álbum }\end{array}$ & 5 & 66 & $\begin{array}{l}\text { Trabajo en } \\
\text { equipo. } \\
\text { Compañerismo. } \\
\text { Desarrollo de la } \\
\text { imaginación. }\end{array}$ \\
\hline $\begin{array}{l}\text { El monstruo de } \\
\text { colores }\end{array}$ & Anna Llenas & Anna Llenas & Flamboyant & $\begin{array}{l}\text { Narrativa } \\
\text { Álbum }\end{array}$ & 5 & 54 & $\begin{array}{l}\text { Emociones. } \\
\text { Fomenta la } \\
\text { empatía. }\end{array}$ \\
\hline $\begin{array}{l} \\
\text { Por cuatro } \\
\text { esquinitas de } \\
\text { nada }\end{array}$ & $\begin{array}{l}\text { Jérôme } \\
\text { Ruillier }\end{array}$ & Jérôme Ruillier & $\begin{array}{l}\text { Editorial } \\
\text { Juventud }\end{array}$ & $\begin{array}{l}\text { Narrativa } \\
\text { Álbum }\end{array}$ & 6 & 45 & $\begin{array}{ll}\text { Diversidad, } & \\
\text { respeto } & \text { y } \\
\text { solidaridad. } & \\
\text { Amistad. } & \\
\text { Valores, } & \\
\text { igualdad } & \text { e } \\
\text { integración. } & \end{array}$ \\
\hline Elmer & D. McKee & D. McKee & Beascoa & $\begin{array}{l}\text { Narrativa } \\
\text { Álbum } \\
\text { Prelectura y } \\
\text { preescritura }\end{array}$ & 3 & 38 & $\begin{array}{l}\text { Trabajo de la } \\
\text { diversidad. }\end{array}$ \\
\hline $\begin{array}{l}\text { Orejas de } \\
\text { mariposa }\end{array}$ & Luisa Aguilar & André Neves & Kalandraka & $\begin{array}{l}\text { Narrativa } \\
\text { Álbum }\end{array}$ & 6 & 38 & $\begin{array}{l}\text { Refuerzo de la } \\
\text { autoestima. } \\
\text { Cómo afrontar } \\
\text { las burlas. } \\
\text { Tratar las } \\
\text { diferencias. } \\
\text { Complejos. }\end{array}$ \\
\hline $\begin{array}{l}\text { El cazo de } \\
\text { Lorenzo }\end{array}$ & $\begin{array}{l}\text { Isabelle } \\
\text { Carrier }\end{array}$ & Isabelle Carrier & $\begin{array}{l}\text { Editorial } \\
\text { Juventud }\end{array}$ & $\begin{array}{l}\text { Narrativa } \\
\text { Álbum }\end{array}$ & 5 & 25 & $\begin{array}{l}\text { Diversidad. } \\
\text { Prejuicios. } \\
\text { Actitud } \\
\text { positiva ante } \\
\text { las diferencias } \\
\text { individuales. }\end{array}$ \\
\hline La cebra Camila & Marisa Núñez & Óscar Villán & Kalandraka & $\begin{array}{l}\text { Narrativa } \\
\text { Álbum } \\
\text { Prelectura y } \\
\text { preescritura }\end{array}$ & 4 & 24 & $\begin{array}{l}\text { Solidaridad. } \\
\text { Emociones. } \\
\text { Trabajo de las } \\
\text { diferencias. } \\
\text { Obediencia a } \\
\text { los adultos. }\end{array}$ \\
\hline $\begin{array}{l}\text { El libro negro de } \\
\text { los colores }\end{array}$ & $\begin{array}{l}\text { Menena } \\
\text { Cottin }\end{array}$ & Rosana Faria & $\begin{array}{l}\text { Libros del } \\
\text { Zorro Rojo }\end{array}$ & $\begin{array}{l}\text { Otro } \\
\text { Álbum }\end{array}$ & 5 & 23 & $\begin{array}{l}\text { Despierta la } \\
\text { creatividad y la } \\
\text { imaginación. } \\
\text { Trabajo de la } \\
\text { discapacidad } \\
\text { visual. }\end{array}$ \\
\hline & & & & Narrativa & & & \\
\hline
\end{tabular}




\begin{tabular}{|c|c|c|c|c|c|c|c|}
\hline Soy el más fuerte & Mario Ramos & Mario Ramos & Corimbo & \begin{tabular}{|l|} 
Álbum \\
Prelectura y \\
preescritura
\end{tabular} & 3 & 14 & $\begin{array}{l}\text { Cuento ameno } \\
\text { y divertido. }\end{array}$ \\
\hline $\begin{array}{l}\text { ¿Hay algo más } \\
\text { aburrido que ser } \\
\text { una princesa } \\
\text { rosa? }\end{array}$ & $\begin{array}{l}\text { Raquel Díaz } \\
\text { Reguera }\end{array}$ & $\begin{array}{|lr|}\text { Raquel } & \text { Díaz } \\
\text { Reguera } & \\
\end{array}$ & Thule & $\begin{array}{l}\text { Narrativa } \\
\text { Álbum }\end{array}$ & 5 & 14 & $\begin{array}{l}\text { Ruptura } \\
\text { estereotipos. } \\
\text { Trabajar la } \\
\text { coeducación }\end{array}$ \\
\hline $\begin{array}{l}\text { El topo que } \\
\text { quería saber } \\
\text { quien se había } \\
\text { hecho aquello en } \\
\text { la cabeza }\end{array}$ & $\begin{array}{l}\text { Werner } \\
\text { Holzwarth }\end{array}$ & Wolf Erlbruch & $\begin{array}{l}\text { Alfaguara } \\
\text { Infantil }\end{array}$ & \begin{tabular}{|l|} 
Narrativa \\
Álbum \\
Prelectura y \\
preescritura
\end{tabular} & 4 & 13 & $\begin{array}{l}\text { Trata los temas } \\
\text { escatológicos } \\
\text { con } \\
\text { naturalidad. }\end{array}$ \\
\hline $\begin{array}{l}\text { Pequeño azul y } \\
\text { pequeño amarillo }\end{array}$ & Leo Lionni & Leo Lionni & Kalandraka & $\begin{array}{l}\text { Narrativa } \\
\text { Álbum } \\
\begin{array}{l}\text { Prelectura y } \\
\text { preescritura }\end{array}\end{array}$ & 4 & 13 & $\begin{array}{l}\text { Desarrolla la } \\
\text { creatividad. } \\
\text { Valores: } \\
\text { amistad, } \\
\text { igualdad, } \\
\text { respeto. } \\
\text { Imaginación y } \\
\text { creatividad. } \\
\text { Trabajo de las } \\
\text { diferencias. }\end{array}$ \\
\hline Un libro & Hervé Tullet & Hervé Tullet & Kókinos & $\begin{array}{l}\text { Otro } \\
\text { Libro-juego }\end{array}$ & 1 & 13 & $\begin{array}{l}\text { Formas y } \\
\text { colores. } \\
\text { Fomenta } \\
\text { creatividad e } \\
\text { imaginación. }\end{array}$ \\
\hline $\begin{array}{l}\text { La pequeña } \\
\text { oruga glotona }\end{array}$ & Eric Carle & Eric Carle & Kókinos & \begin{tabular}{|l|} 
Narrativa \\
Álbum \\
Prelectura y \\
preescritura
\end{tabular} & 2 & 12 & $\begin{array}{l}\text { Narración } \\
\text { sencilla. } \\
\text { Aprendizaje de } \\
\text { números, frutas } \\
\text { y días de la } \\
\text { semana. } \\
\text { Metamorfosis. } \\
\text { Vida saludable. }\end{array}$ \\
\hline El principito & \begin{tabular}{|l} 
Antoine de \\
Saint- \\
Exupéry
\end{tabular} & $\begin{array}{l}\text { Antoine de } \\
\text { Saint-Exupéry }\end{array}$ & Salamandra & $\begin{array}{l}\text { Narrativa } \\
\text { (versión } \\
\text { pop-up) }\end{array}$ & 9 & 11 & $\begin{array}{l}\text { Trabajo de la } \\
\text { socialización. }\end{array}$ \\
\hline El pollo Pepe & \begin{tabular}{|l} 
Nick \\
Denchfield y \\
Ant Parker
\end{tabular} & $\begin{array}{l}\text { Nick } \\
\text { Denchfield y } \\
\text { Ant Parker }\end{array}$ & SM & $\begin{array}{l}\text { Narrativa } \\
\text { (versión } \\
\text { pop-up) } \\
\text { Prelectura y } \\
\text { preescritura }\end{array}$ & 1 & 10 & $\begin{array}{l}\text { Animales y los } \\
\text { alimentos. } \\
\text { Espacialidad, } \\
\text { tamaños y } \\
\text { cantidades. }\end{array}$ \\
\hline $\begin{array}{l}\text { Todos somos } \\
\text { especiales }\end{array}$ & $\begin{array}{l}\text { Arlene } \\
\text { Maguire }\end{array}$ & Arlene Maguire & Everest & \begin{tabular}{|l|} 
Poesía* \\
Prelectura y \\
preescritura
\end{tabular} & 3 & 10 & Diversidad. \\
\hline
\end{tabular}

Tabla 2. Libros con 10 elecciones o más 
Cuando se observan los motivos por los que los alumnos dicen elegir estas obras para incluirlas en su biblioteca de aula, llama la atención que, de manera generalizada, se destacan las finalidades prácticas de las mismas, sin resaltar apenas las posibilidades de diversión que supone el acercamiento a la literatura que ofrecen a los más pequeños y que se debería situar en la base de cualquier selección de textos literarios si lo que se persigue es formar/crear futuros lectores. No en vano, si tenemos en cuenta lo que marca el currículo respecto al tratamiento de la literatura en el aula de Educación Infantil se aprecia que es precisamente el tratamiento de esta como elemento destinado al disfrute lo que predomina en los documentos legales. De manera concreta en el Real Decreto 1630/2006 se insiste en la necesidad de fomentar "un acercamiento a la literatura infantil, a partir de textos comprensibles y accesibles para que esta iniciación literaria sea fuente de goce y disfrute, de diversión y de juego" (BOE, $\mathrm{n}^{\circ} 4$ de 4 de enero de 2007, p, 480). De igual modo, en la concreción andaluza del Decreto se marca que "El fin de los textos literarios es hacer disfrutar al lector a través de la belleza del lenguaje", (BOJA, $\mathrm{n}^{\mathrm{o}} 169$ de 26 de agosto de 2008, p. 42), esta idea que se halla incluida en el desarrollo del currículo del área de "Lenguajes: comunicación y representación" para el primer ciclo se mantiene en lo dicho para el segundo ciclo, pues se destaca allí la importancia de las lecturas para acercar al niño a la literatura de manera que pueda "vivenciar" lo narrado y "enamorarse" del lenguaje literario, a lo que deben ayudar también las dramatizaciones y los recitados de poemas, todo ello al tiempo que se va acercando a los niños a los elementos propios de su cultura (BOJA, no 169 de 26 de agosto de 2008, p. 42).

En este punto, convendría matizar que si bien la utilidad o no de la obra se sitúa como algo clave en su selección, cuando se trata de obras poéticas esto pasa a ser algo secundario en el conjunto de las citadas por los alumnos, salvo en el caso de Todos somos iguales, y así es el acercamiento al género o la diversión que puede proporcionar la lectura del texto lo que se destaca como elemento principal en la elección de un determinado título. Varios de los títulos del género poético citados pertenecen a la colección De la cuna a la luna de Kalandraka con textos de Antonio Rubio e ilustraciones de Óscar Villán, aunque tampoco faltan aquí obras de Gloria Fuertes, Carlos Reviejo, Carmen Gil, Antonio Gómez Yebra y referentes de la poesía en general como Federico García Lorca o Antonio Machado, que se citan a partir de ediciones específicas para niños (12 poemas de Federico García Lorza de Kalandraka y Antonio Machado para niños y niñas y otros seres curiosos de Ediciones de la Torre). La presencia de estas obras guarda relación con lo recogido en el currículo sobre el empleo de la literatura en general y de la poesía en particular como vehículo para acercar al alumno a la cultura andaluza (BOJA, no 169 de 26 de agosto de 2008, p. 42). Algo parecido sucede con las escasas obras teatrales que se citan, donde 9 elecciones se reparten entre cinco obras, en las que junto a una versión para representar de Blancanieves figuran el Circo de la fantasía, El espantapájaros amigo de los pájaros de Yolanda Prieto y Ramiro Pinto, La bruja piruja de Daniel Montero Galán y Carlos Blanco o el Teatro para niños de Gloria Fuertes.

También es el empleo de los textos como fuente de diversión lo que predomina en la selección hecha de los denominados libros-juego o libros interactivos como Un libro, Veo veo ¿un caracol?, La cocina de la bruja, ¿Dos ojos?, La cocina de dibujos, Un libro inquieto, etc., o aquellos otros que persiguen cautivar la atención del niño con la 
potencia de sus imágenes y que podrían emplearse como acompañamiento para acercarlo a la literatura tradicional, como sucede con la edición de escenas de cuentos creada por Benjamin Lacombe y publicada por Edelvives con el título de Cuentos silenciosos.

De lo visto hasta aquí parece claro que en la selección hecha por los alumnos se basa sobre todo en principios utilitaristas de la creación literaria y solo excepcionalmente se reconoce el valor de esta como un material destinado al disfrute como se hace en el caso de Soy el más fuerte. En este sentido nos gustaría destacar la inclusión de la obra $E l$ topo que quería saber quién se había hecho aquello en su cabeza, hacia la que los alumnos mostraron inicialmente bastantes reticencias cuando se les enseñó el libro en clase por entender que no fomentaba un comportamiento ejemplar y tras reflexionar sobre el uso lúdico de la misma ha acabado entre las más elegidas.

Habría que indicar que varias de las obras recogidas entre las más leídas las habían trabajado en otras asignaturas del Grado en Educación Infantil por su utilidad como textos que fomentaban la inclusión, la igualdad de géneros o la aceptación de la diversidad, entre otras cuestiones, y son estos elementos son los que recurrentemente figuran en buena parte de la selección de textos. De igual modo, las posibilidades del uso de la literatura para trabajar diferentes aspectos del currículo, tal y como recoge la propia legislación, hace que la vertiente utilitarista en la selección de obras sea aún más acusada. Pueden verse al respecto las referencias hechas a los textos literarios, y de manera más marcada al cuento y la poesía, como instrumento para acercar al niño a su entorno, para aprender a relacionarse, acercarse a su cultura, mejorar la expresión oral y escrita, además de propiciar el disfrute lector, en los tres bloques en los que se divide el currículo - pueden verse de a modo de ejemplo las páginas 34, 37, 40 y 42 de la Orden del 5 de agosto de 2008 (BOJA, no 169 de 26 de agosto de 2008, donde se mencionan todos estos aspectos-.

A esto último habría que sumar la influencia que pudiese tener la propia descripción que ofrecen las editoriales en las sinopsis de los textos, donde suelen insistir en la utilidad de los mismos como fuente de conocimiento de determinados conceptos.

Tenemos, no obstante, la esperanza de que el acercamiento y el disfrute de la literatura sea algo que se esté dando por una cuestión implícita, aunque el hecho de que a veces se destaque, como sucede con géneros como la poesía o el teatro, nos hace sospechar lo contrario. Ahora bien, la importancia que cobra en la selección de obras el álbum ilustrado y la adecuación de estas a la edad de los destinatarios, así como un eventual uso adecuado en la biblioteca de aula a través de actividades destinadas a la animación a la lectura, puede propiciar el desarrollo de esa lectura literaria que caracterizan Mata y Lomas (2014) a partir de los testimonios y opiniones de los docentes y que, en definitiva, trata de superar el empleo de la literatura como pretexto para la enseñanza de determinados conceptos (instrucción) o para el trabajo de cuestiones relacionadas con la socialización del individuo (moralización). Esto último contribuiría a acercar al niño al lenguaje literario como fuente de disfrute, dejando que con sus lecturas e interpretaciones vaya dando por sí mismo significado a los textos, definiendo sus gustos lectores y con ello formando su competencia literaria. 
ANEXO 1. Editoriales presentes en la selección de los alumnos:

En función de los datos contenidos en los gráficos y tabla resulta claro que son editoriales como Kalandraka, Flamboyant, Editorial Juventud, Kókinos, SM, Alfaguara Infantil, Everest, Beascoa, Salamandra, Corimbo o Libros del Zorro Rojo las mayoritariamente elegidas, pero si se recogen los datos globales de la selección se producen algunos cambios, pues allí los diez primeros puestos los ocupan: Kalandraka, Editorial Juventud, Flamboyant, Kókinos, Beascoa, SM, Edelvives, Libros del zorro rojo, Thule Ediciones y Alfaguara Infantil —esta última condenada ya a desaparecer reconvertida en Loqueleo desde finales de 2015-.

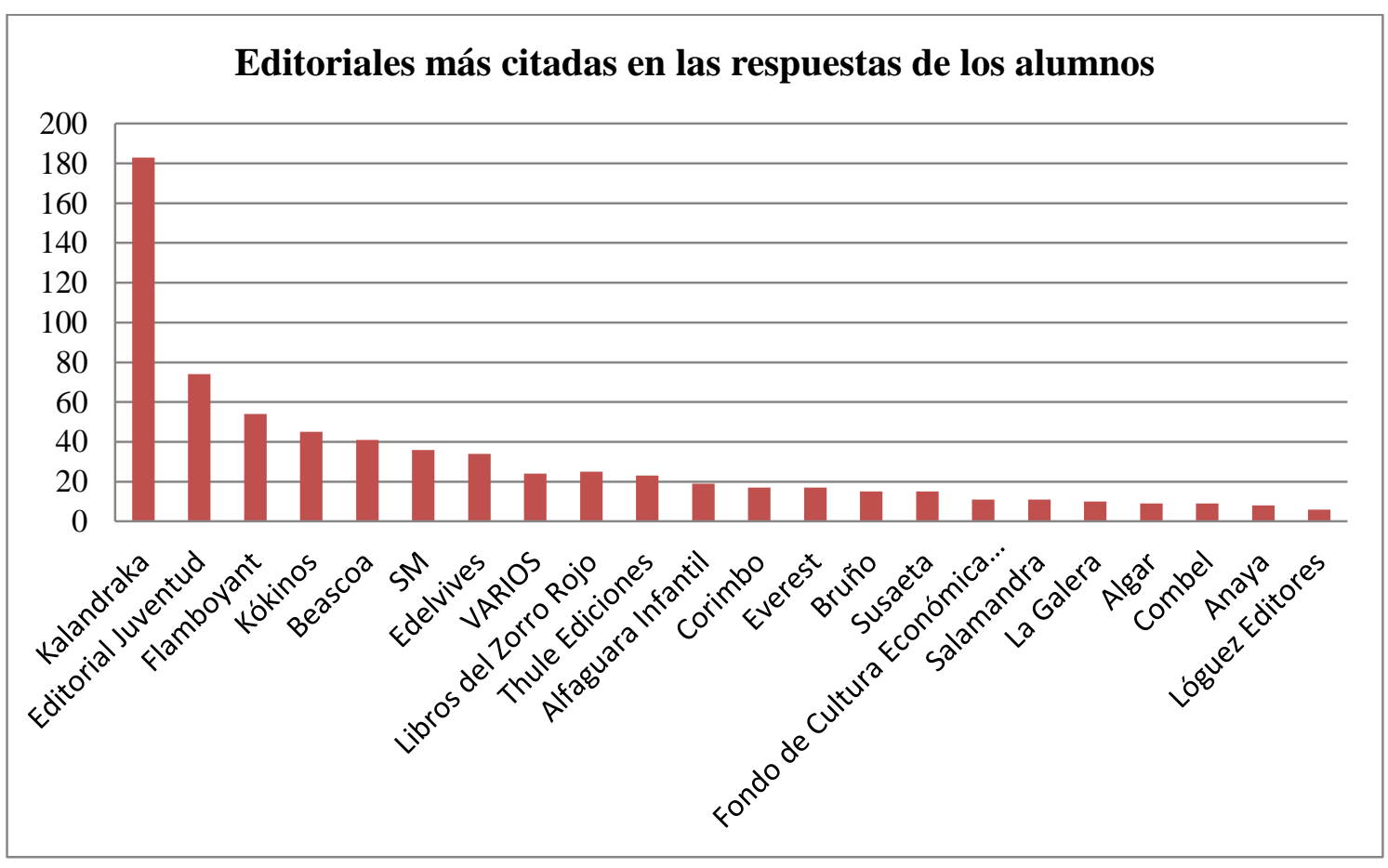

Figura 5. Editoriales con más de cinco elecciones según las respuestas de los alumnos

[Bajo el rótulo de varios figuran aquellas obras que por tratarse de cuentos tradicionales en su mayoría no ha sido posible determinar quién fue el responsable último de su edición]

Además de las incluidas aquí en las respuesta se citaron las siguientes: Amigos de Papel e Imaginarium con 5 selecciones; A buen paso, Escuela Española, Lumen, Palabras Aladas y Serres con 4; Cuento de Luz, Diputación de Málaga, Edebé, Ediciones de la Torre, GEU, TCC Trébol Comunicación y Creación S.A., Movilh, OQO Editora y Planeta con 3; Bárbara Fiore, Ediciones B, Ediciones Destino, Ediciones Gaviota, Editorial CCS, Macmillan, Océano, Parramón, Takatuka y Usborne con 2 y Bayard Revistas, Bellaterra, CIDCLI INFANTIL, SmashWords Edition (ebook), Ediciones Aljibe, Ediciones Fortuna, El Jinete Azul, Entrelibros, Espasa, Grafalco, Hiperión, Intermón Oxfand, Larousse, Libre Albedrío, Maestra Indantil (EDIBA), Mestas Ediciones, Mil Razones, Molino, Narval, Obelisco, Palabras del Candil, Penguin, 
Phaidon, Plaza \& Jane, Principal de los Libros, RBA Libros, S. L. U., Salvatella, Tàndem Editores, Versos y Trazos, Walt Disney y Zendrera Zariquiey; a lo que se suma un libro de autoedición y otro de la web del autor.

Si consideramos el número de obras diferentes citadas, los diez primeros puestos los ocupan: Kalandraka con 28, SM con 16, Kókinos y Edelvives con 13 cada una, Susaeta con 9, Anaya y Everest con 8, Combel y La Galera con 7 y Bruño con 5 obras distintas.

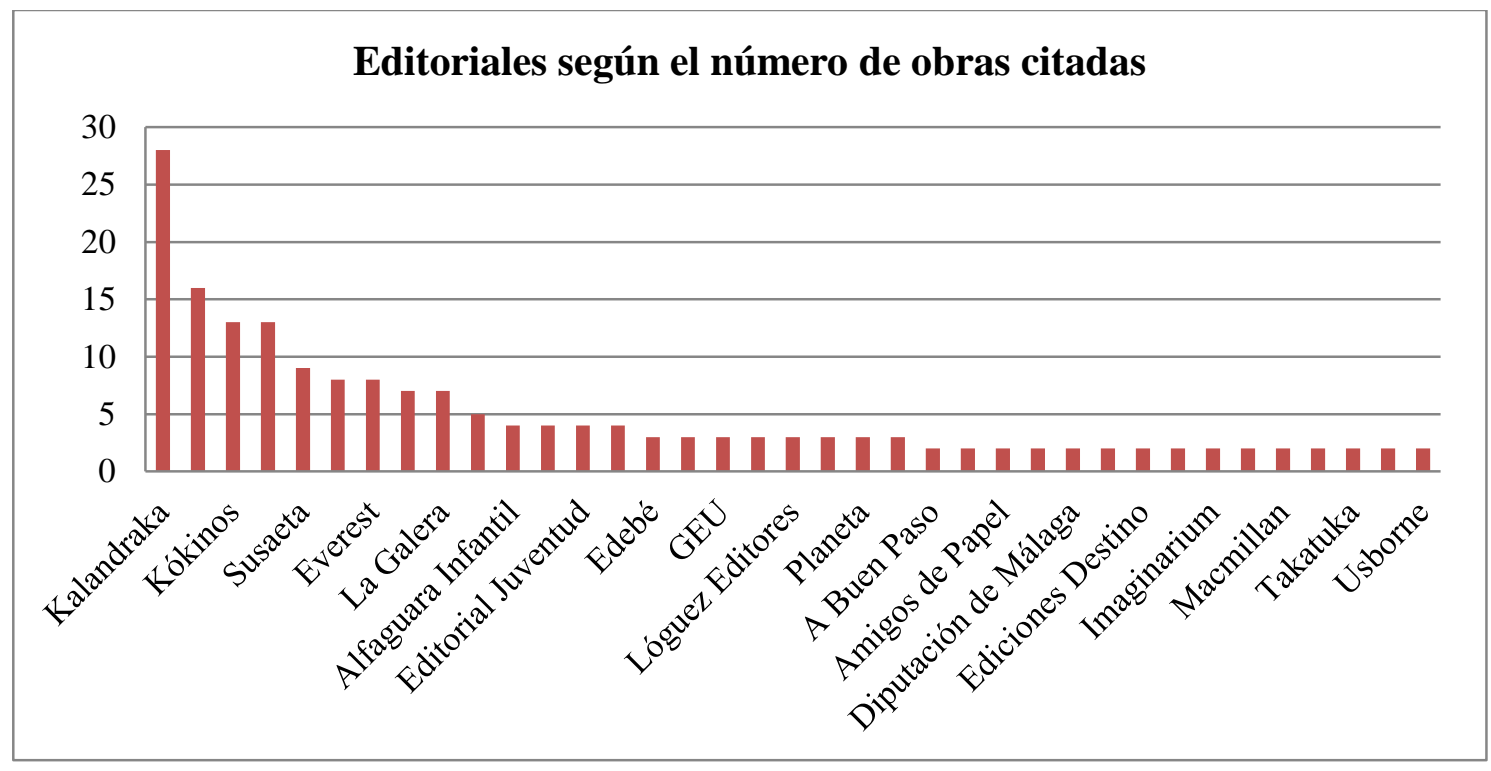

Figura 6. Editoriales con dos obras o más.

Con una sola obra elegida estarían las siguientes: Bárbara Fiore, Bayard Revistas, Bellaterra, CIDCLI INFANTIL, Cuento de Luz, Ediciones Aljibe, Ediciones B, Ediciones Fortuna, Editorial CCS, El Jinete Azul, Entrelibros, Espasa, Flamboyant, Grafalco, Hiperión, Intermón Oxfand, Larousse, Libre Albedrío, Mestas Ediciones, Maestra Infantil (EDIBA), Mil Razones, Molino, Movilh, Narval, Obelisco, Océano, Palabras Aladas, Palabras del Candil, Penguin, Phaidon, Plaza \& Jane, Principal de los Libros, RBA Libros, S. L. U., Salamandra, Salvatella, SmashWords Edition. Ebook, Tàndem Editores, TCC Trébol Comunicación y Creación S.A., Versos y Trazos, Walt Disney y Zendrera Zariquiey; además de un texto en autoedición y otro obtenido desde la web del autor, a lo que se suman 14 obras de las que por tratarse de clásicos o por existir en más de una editorial ha sido imposible incluir el dato. 
ANEXO 2. Autores presentes en la selección de los alumnos

Entre los autores, los más elegidos serían los que se hallan en la tabla inicial, pero si establecemos una relación entre las obras que se citan de cada uno, vemos que se producen notables variaciones, pues entre los diez primeros se situarían Gloria Fuertes con 11 obras, Antonio Rubio con 5, los hermanos Grimm con 5, Begoña Ibarrola y Eric Carle con 4 cada uno, Carlos Reviejo, Giani Rodari, Hervé Tullet y Violeta Monreal con 3 y Adela Turín y otros varios con 2. Estimamos más significativo el primer dato, pues si pensamos que las elecciones corresponderían con los libros presentes en la biblioteca de aula serían los escritores contenidos en el primer gráfico los más trabajados en el aula.

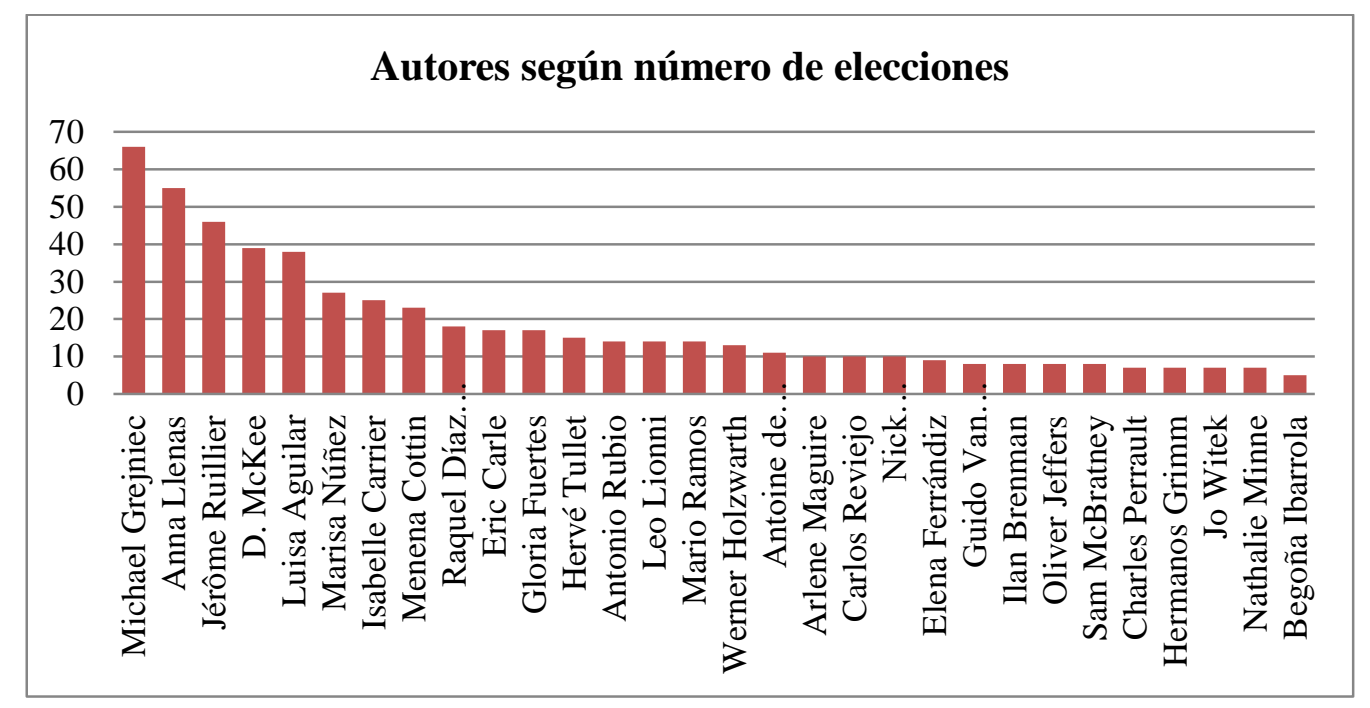

Figura 7. Autores con más de cinco elecciones.

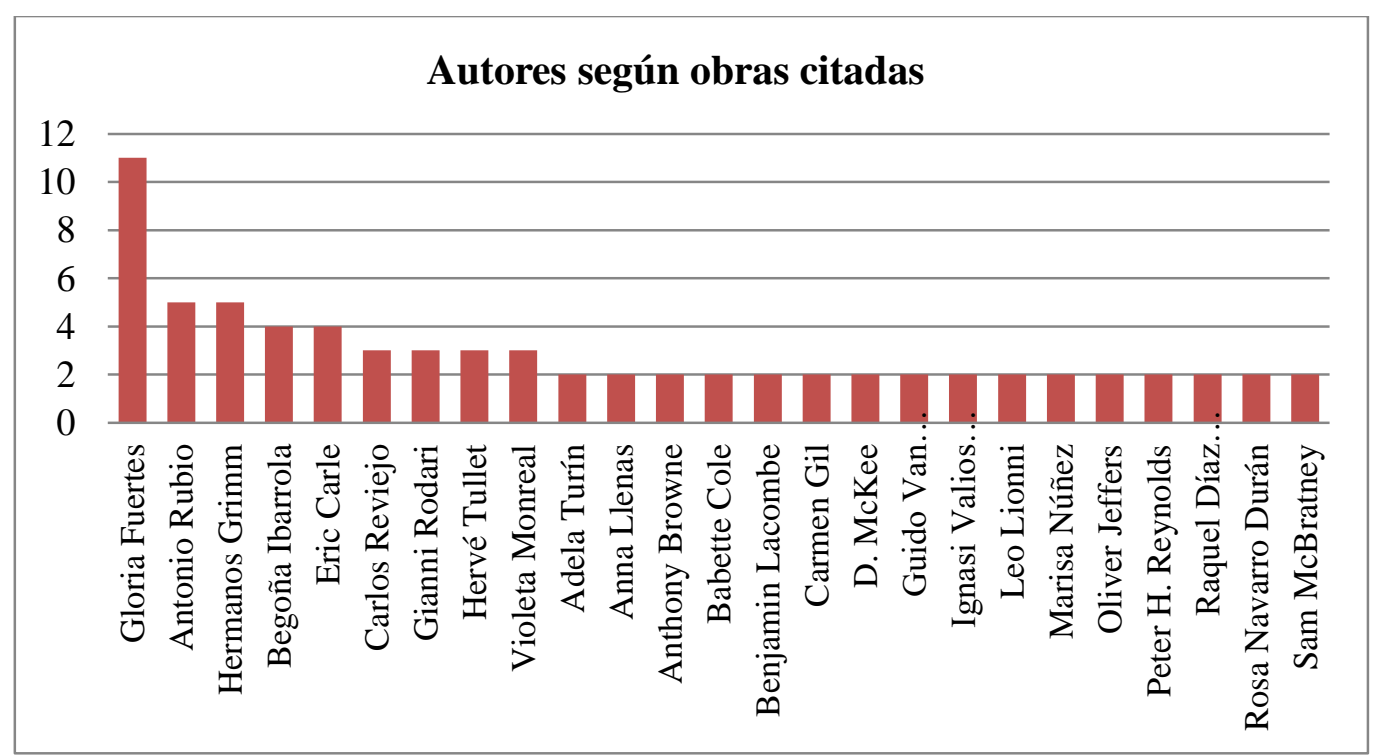

Figura 8. Autores con más de dos obras citadas [el resto tiene una sola obra] 
Además de los indicados figuran: Adela Turín, Benjamin Lacombe, Concha López Narváez y Fernando Lalana, Cristina Núñez y Rafael R. Valcarcel. Daniel Montero Galán y Carlos Blanco, Elisenda Queralt, Gianni Rodari, Maurice Sendak y Mon Laporta, con cuatro elecciones cada uno; Cali Davide, Ellie Bethel, Gemma Linares, Gonzalo Maure Trenor, Irene Aparici, Juan Arjona, Leslie Nicholls y Ramón Gómez, Marcus Pfister, Peter H. Reynolds, Philippe Lecheirmeier, Ramiro Pinto Cañón y Yolanda Prieto Martínez, Txabi Arnal Gil y Violeta Monreal, con tres; Agnese Baruzzi, Angels Navarro, Anthony Browne, Antonio Machado, Babette Cole, Carmen Gil, Carmen Queralt, Ed Emberly, Elisenda Roca, Eva Mejuto, Federico García Lorca, Gabriela Keselman, Ignasi Valios Buñuel, Istvan Banyai, Jesús Jarque García, Ken Kimura, Krestin Schoene, Liesbet Slegers, Nadia Shireen, Pat Hutchins, Reinaldo Jiménez Morales, Rosa Navarro Durán, Sonia Castelletti y Tim Bowley, con dos y, finalmente, Ainara Calvo Llorente, Aline de Petigny, Andy Cutbill, Ángeles GonzálezSinde, Anita Jeram, Antoinette Portis, Antonio Gómez Yebra, Antonio Rodríguez Almodóvar y JoséAntonio Francés, Asun Balzola, Beatriz Berrocal Pérez, Beatriz Gimenez de Ory, Bill Martin, Carl Norac, Cláude K. Dubois, Carla Riba, Carlos Granada, Carmela Lavigna, Carmen Martín Anguita, Carmen Miquel Riego, Carmen Parets Luque, César García Muñoz, Cheryl Kilodavis, Christian Voltz, Claire Page y Nick Page, Colette Hellings, David Melling, Eduard Estivill y Montse Domenech, Elena Angulo, Sergi Càmara, Eliacer Cansino, Emilio Urberuaga, Ernst Jandl, Esteban Cabezas, Félix Albo, Fermín Solís, Francesc Rigol, Francesca Di Chiara, Francisco Capdevila Blanco, Georgina Lazaro, Hans Christian Andersen, Heather Miller, Iban Barrenetxea, Ingo Siegner, Jane Ray, Janosch, Jeanette Randerath, Jean-Marc Derouen, Jen Green, Jennifer Berne, Jon Klassen, Jonny Zucker, Jorge Luján, Juan José Jurado, Juan Ramón Brotons, Juana Neira, Julia Donaldson, Jürg Schubiger, Liebet Slegers, Lucie Felix, $\mathbf{M}^{\mathrm{a}}$ del Pilar Ramos y $\mathbf{M}^{\mathrm{a}}$ Teresa Ramos, Manuel Fernández Álvarez, Mar Benegas, Mar Ferrero, Marco Berrettoni Carrara, Martin Tylor, Michel Van Zeveren, Miquel Desclot, Mirelle D'Allaçe, Miriam Moss, Mo Willems, Munro Leaf, Nathalie Choux, Nathalie Dieterle, Neville Astley, Nick Sharrat, Paco Capdevilla, Paloma Bordons, Pedro Pablo Sacristán, Pere Ginard, Peter Harris, Pilar Lozano, Ray Bradbury, Rina Singh, Roberto Kruger González, Rosa Tiziano Bruno, Roser Rius Camps, Sandra Grimm, Santi Balmes, Satoe Tone, Steve Cox, Svjetlan Junakovic, Sylvia Dupuis, Teresa Soler, Tessie Solinis, Thando Maclaren, Thris Phillips, Tomie de Paola, Tracey Moroney, Vela, Utrera y Sasian, Violeta Denou, Xavi Gutiérrez, Xosé Antón Ballesteros y Xosé Manuel González "Oli", con una obra. A todos ellos hay que sumar 9 obras de equipos editoriales y 5 textos correspondientes a relatos tradicionales de los que fue imposible determinar incluso la empresa encargada de su tirada.

\section{Referencias Bibliográficas}

Cervera, J. (1991). Teoría de la Literatura Infantil. Bilbao: Ed. Mensajero Universidad de Deusto.

Colomer, T. y Durán, T., (2001). La literatura en la etapa de educación infantil. En Montserrat Correig y Montserrat Bigas (Coords.). Didáctica de la lengua en educación infantil (pp. 213-250). Madrid: Síntesis.

Durán, T. (2007). El álbum: un modelo de narratología postmoderna, Primeras Noticias. Literatura Infantil y Juvenil, 230, 31-38. 
Hoster, B. y Lobato $\mathrm{M}^{\mathrm{a}}$ J. (2007):.Iniciación a la competencia literaria y artística a través del álbum ilustrado. Lenguajes y textos, 26, 119-134.

LEY ORGÁNICA 2/2006, de 3 de mayo, de Educación. Boletín Oficial del Estado, no 106 de 4 de mayo de 2006.

LEY ORGÁNICA 8/2013, de 9 de diciembre, para la mejora de la calidad educativa. BOE, núm. 295 de 10 de diciembre de 2013.

Mata, J. (2014). El aprendizaje de la lectura literaria. Encuesta a especialistas en educación literaria, Textos de Didáctica de la Lengua y de la Literatura, 66, 4249.

Mendoza Fillola, A. (2008). Función de la literatura infantil y juvenil en la formación de la competencia literaria ([1999], pp.11-53). En P. Cerrilo y J. García Padino (Coords.). Literatura infantil y su didáctica. Cuenca: Universidad de Castilla-La Mancha, [Alicante: Biblioteca Virtual Miguel de Cervantes]. Recuperado el 13 de Junio de 2016, de http://cort.as/qRIY

ORDEN de 5 de agosto de 2008, por la que se desarrolla el Currículo correspondiente a la Educación Infantil en Andalucía. Boletín Oficial de la Junta de Andalucía, ${ }^{\circ}$ 169 de 26 de agosto de 2008.

REAL DECRETO 1630/2006, de 29 de diciembre, por el que se establecen las enseñanzas mínimas del segundo ciclo de Educación Infantil. Boletín Oficial del Estado, $\mathrm{n}^{\mathrm{o}}$ 4, de 4 de enero de 2007. 